\title{
A SIMPLE TECHNIQUE FOR VARUS SUPRACONDYLAR OSTEOTOMY IN GENU VALGUM
}

\author{
IAN D. LEARMONTH
}

From Princess Alice Orthopaedic Hospital, University of Cape Town

\begin{abstract}
Varus osteotomy of the distal femur is recommended for osteoarthritis of the knee with significant valgus deformity, but the operation is difficult to plan and perform.

A simple technique involving a jig referenced to the line of the tibia is described. This allows accurate overcorrection by a few degrees, with impaction and secure fixation at the osteotomy. It has been successful, with no complications, in 12 consecutive knees.
\end{abstract}

Varus osteotomy of the distal femur for valgus deformity of the knee due to lateral compartment osteoarthritis is well established, but accuracy in the technique has always provided a challenge. In a knee with valgus deformity, the tibiofemoral angle leads to an inclination of the joint line. Correction of the valgus deformity by varus osteotomy below the joint will increase this inclination and lead to lateral subluxation of the tibia. This observation led Coventry in 1973 to state that if the valgus deformity exceeded $12^{\circ}$ or if the projected obliquity of the joint line was more than $10^{\circ}$, then a varus osteotomy of the distal femur is preferable to a varus osteotomy of the proximal tibia.

Deciding on, and achieving the correct angle can both be difficult. We present a simple technique for providing appropriate and reproducible correction. The method is based on the fact that the normal tibiofemoral angle is $5^{\circ}$ to $8^{\circ}$ of valgus. Therefore, correction of alignment so that femur and tibia are anatomically colinear will result in $5^{\circ}$ to $8^{\circ}$ of mechanical varus, and effectively unload the lateral compartment.

\section{SURGICAL TECHNIQUE}

The patient is placed supine with, if there is no contraindication, a tourniquet on the proximal thigh. A $15 \mathrm{~cm}$ medial longitudinal incision is made, ending distally at the level of the medial joint line. The fascia over vastus

I. D. Learmonth, FRCS, FCS (SA) Orth, Head of Rheumatology Surgical Service

Princess Alice Orthopaedic Hospital, Private Bag, Plumstead 7800 , Cape Town, Republic of South Africa.

(C) 1990 British Editorial Society of Bone and Joint Surgery $0301-620 \mathrm{X} / 90 / 2032 \$ 2.00$

J Bone Joint Surg [Br] 1990; 72-B :235-7. medialis is incised and the muscle is mobilised off the intermuscular septum and reflected anteriorly and laterally to expose the medial aspect of the femoral shaft. The distal aspect of the medial surface of the femoral condyle is exposed, using subperiosteal Hohmann retractors. A special jig (Fig. 1) is applied to the anterior tibial crest, referencing the long axis of the bone. It has a proximal cradle which is placed so as to embrace the femoral condyles. A Steinmann's pin is then directed into the femur at right angles to the long axis of the tibia through the appropriate sleeve in the cradle (Fig. 2), the threaded sleeve being advanced to contact the bone. The level of the pin in relation to the joint line is controlled fluoroscopically. It is placed well into the bone and then used as a guide for a seating chisel which is introduced into the medial condyle and advanced into the lateral condyle. It must remain exactly parallel to the Steinmann's pin. The pin is removed and a supracondylar

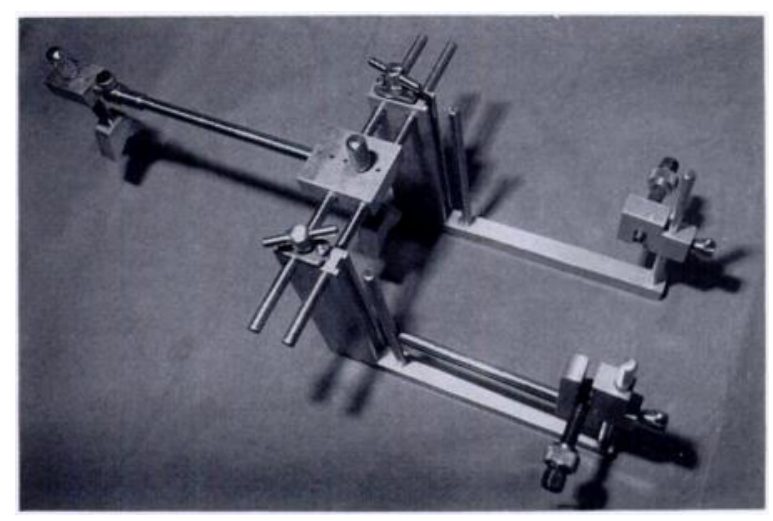

Fig. 1

The jig has a distal longitudinal bar which is seated on the tibial crest to reference the long axis of the bone. The arms of the proximal cradle are on either side of the knee. 
osteotomy is performed at least $2.5 \mathrm{~cm}$ proximal to the blade. A very small medially-based wedge is removed which divides the cortex and allows for later impaction. (Fig. 3). The osteotomy may be facilitated by preliminary drilling of the cortical bone.

A $90^{\circ} \mathrm{AO}$ osteotomy plate is then selected. Blade lengths of 40,50 and $60 \mathrm{~mm}$ are available with each of 10,15 or $20 \mathrm{~mm}$ offset. Radiographic templates made before operation and the surface shape after impaction of the osteotomy dictate the choice of plate. The blade of the selected plate is then introduced, and the femoral diaphysis approximated, impacted and screwed to the plate (Fig. 3). The tibia and femur are now co-linear; this neutral anatomical axis ensures a mechanical axis of $5^{\circ}$ to $8^{\circ}$ of varus at the knee. The wound is closed in layers over suction drains and a bulky bandage is applied.

\section{PATIENTS AND RESULTS}

Twelve distal femoral osteotomies were performed for painful genu valgum in 11 patients at Princess Alice Orthopaedic Hospital, Cape Town from 1983 to 1988. The mean age at the time of operation was 40 years and the average length of follow-up is 41 months.

In nine of the knees the operation produced a colinear tibiofemoral axis (Fig. 4). Two knees showed $2^{\circ}$ of tibiofemoral valgus and one knee $1.5^{\circ}$, but even in these three knees there was a mechanical varus of from $3^{\circ}$ to $5^{\circ}$.

There were no complications in this small series and all patients had good pain relief. Solid fixation of the osteotomy site permitted early mobilisation; no knee showed a significant loss of movement.

\section{DISCUSSION}

Various complex techniques have been described for the correction of genu valgum by a varus distal femoral osteotomy (Maquet 1976; Müller et al 1979; Healy et al 1988). The planning of these procedures depends on

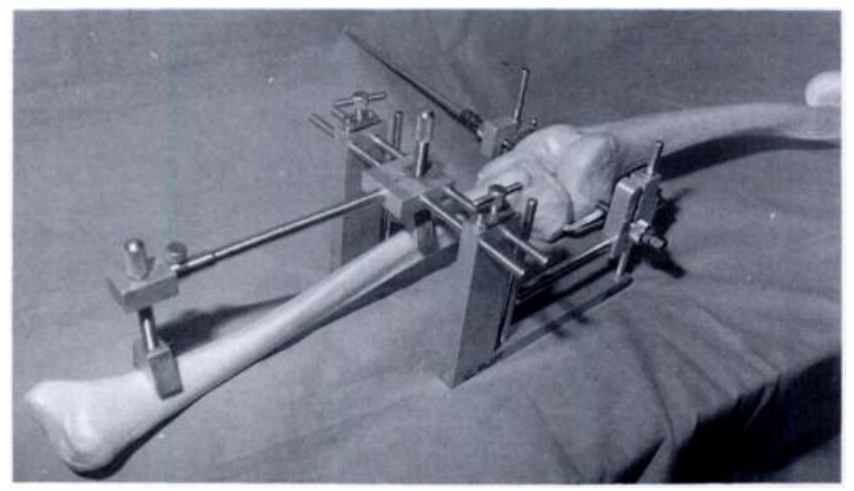

Fig. 2

The jig in position, showing how the Steinmann's pin is inserted at right angles to the long axis of the tibia into the medial femoral condyle just above the joint line.
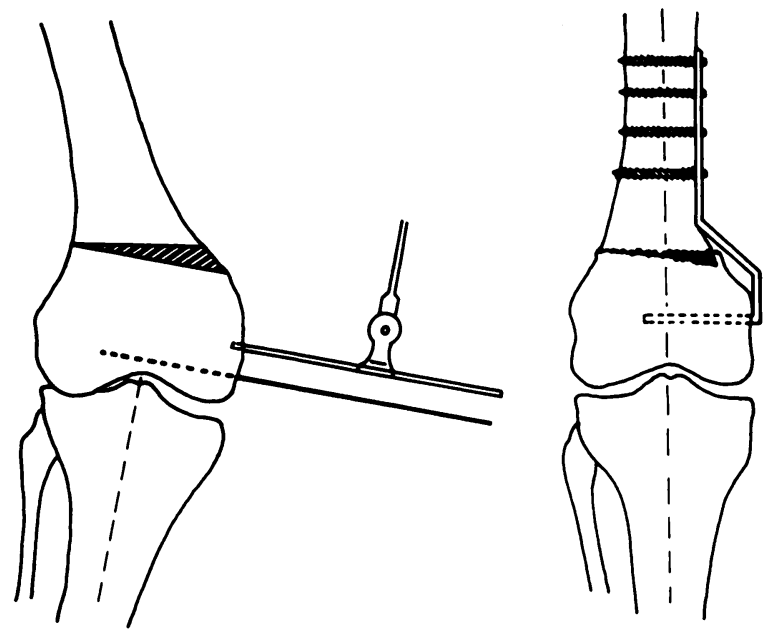

Fig. 3

The seating chisel is inserted parallel to the Steinmann's pin, and a small medially-based wedge is removed $2 \mathrm{~cm}$ proximally. Fixation with a $90^{\circ}$ blade plate ensures impaction at the osteotomy site and a neutral anatomical axis.
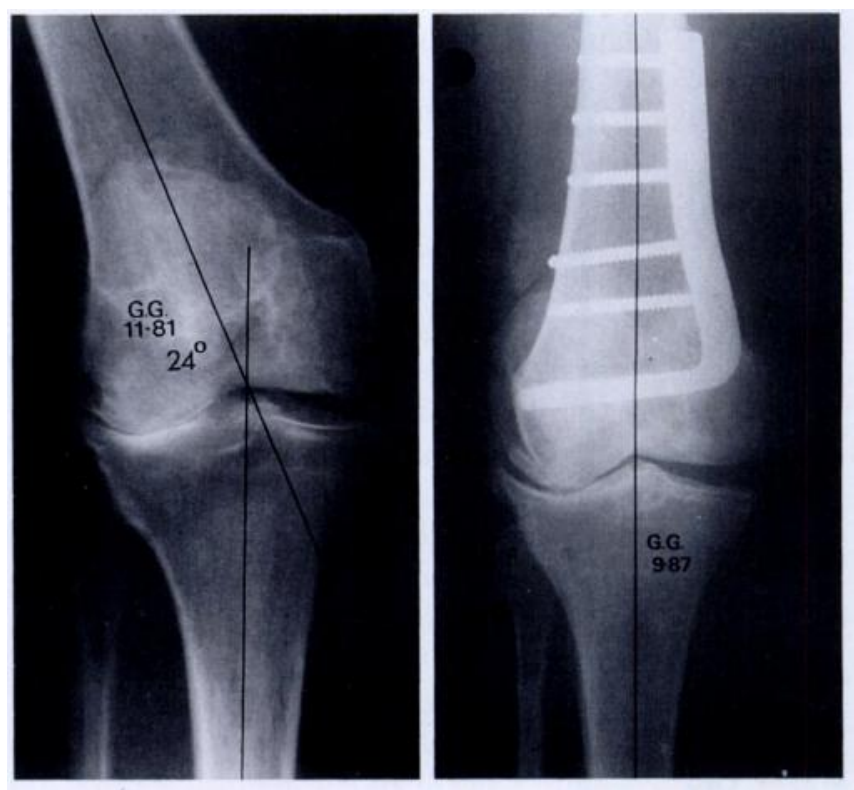

Fig. 4

Radiograph of a 60 -year-old woman with $24^{\circ}$ tibiofemoral valgus. After supracondylar osteotomy the long axes of the tibia and femur are colinear, and the resultant mechanical varus has unloaded the lateral compartment of the knee.

accurate measurements on the pre-operative weightbearing radiographs, but the apparent alignment on these can be altered by as much as $5^{\circ}$ by internal and external rotation of the tibia.

At operation by these methods a complicated system of guide-wires and templates are used to ensure excision of the precise wedge that will provide the desired correction. Healy et al (1988) reported non-union of the osteotomy in two of 23 distal femoral osteotomies, and 
Johnson and Bodell (1981) reported a similar problem. Such non-union may well be due to a small error in preoperative planning or surgical technique which results in secure fixation of the osteotomy without compression at the bone interface.

The technique I have described is simple and reproducible, and can be performed with any jig that references the long axis of the tibial shaft and has a proximal attachment at right angles to this axis. The relative rigidity of the Steinmann's pin and the threaded sleeves on the jig facilitate accurate placement of the pin.
The excision of a small medially-based wedge will, because of the distal flare of the femur, permit impaction of the proximal into the distal fragment. Secure fixation and compression of the impacted fragments virtually eliminates non-union.

I would like to thank Mr M. S. Singer for reviewing and Mrs D. Ward for typing the manuscript, Mr M. Wyeth for preparing the illustration and the Cooper-Lowveld Trust of the University of Cape Town Research for financial assistance.

No benefits in any form have been received or will be received from a commercial party related directly or indirectly to the subject of this article.

\section{REFERENCES}

Coventry MB. Osteotomy about the knee for degenerative and rheumatoid arthritis. J Bone Joint Surg [Am] 1973; 55-A :23-48.

Healy WL, Anglen JO, Wasilewski SA, Krackow KA. Distal femoral varus osteotomy. J Bone Joint Surg [ Am] 1988; 70-A:102-9.

Johnson EW Jr, Bodell LS. Corrective supracondylar osteotomy for painful genu valgum. Mayo Clin Proc 1981 ; 56:87-92.
Maquet PGJ. Biomechanics of the knee: with application to the pathogenesis and the surgical treatment of osteoarthritis. Berlin, etc: Springer-Verlag, 1976

Mäller ME, Allgöwer M, Schneider R, Willenegger H. Manual of internal fixation: techniques recommended by the AO Group. 2nd ed. Berlin etc: Springer-Verlag, 1979. 